\title{
LOS RABASSA, UN LINAJE PATRICIO DE VALENCIA MEDIEVAL
}

\author{
Rafael Narbona Vizcaíno
}

Los Rabassa están documentados en Valencia desde el mismo momento en que el territorio cobraba forma de reino cristiano. En 1238 llegan a la ciudad distintos personajes con este apellido. Su condición social es muy distinta en uno u otro caso, y posiblemente las distintas ramas de estos Rabassa no recordarían -si lo hubiese - su grado de parentesco. De todos modos, y según indica Escolano, todos ellos tenían un nexo en común, pues sirvieron a Jaime I en sus campañas de conquista de distintas formas, bien con la pluma o bien con la espada (1).

Entre los ascendientes del linaje encontramos a Bernat Rabassa, escribano de Jaime I en el momento en que Blasco de Alagón ocupaba Burriana (2). Con anterioridad, en 1229, otros personajes habían pasado a Mallorca, de ahí que Berenguer y Pere Rabassa obtuvieran una serie de tierras en las inmediaciones de la ciudad de Palma (3). En 1238 llegan a Valencia formando parte de la nueva administración implantada para organizar el territorio, y posteriormente, en 1240, obtienen heredamientos en Murcia y Orihuela. Del mismo modo, la campaña de 1247 también les proporcionaría tierras en Xàtiva (4).

Entre todos estos personajes y sus futuras líneas de sucesión destacan dos. Una de ellas la constituyen los Rabassa ennoblecidos a principios del siglo XIV,y entre sus integrantes destaca Guillem, comendador de Ulldecona y Torrente, caballero de la Orden de San Juan de Jerusalém (5). En segundo lugar, resalta en importancia la línea de sucesión que vamos a estudiar: los 
Rabassa, de profesión notarios, que desde último cuarto del siglo XIII están documentados en Valencia con Jover (1281), Guillem (1285), y Giner (1288). Especialmente nos interesa este último personaje,Giner Rabassa, notario de Valencia, que en 1290 es introducido por Alfonso III el Liberal en los asuntos de la Curia (6).

La coexistencia de varias ramas del linaje Rabassa en Valencia, pero especialmente las dos apuntadas - la de notarios y la de caballeros - impiden una completa identificación de sus respectivos miembros con los Rabassa citados en las trovas de los caballeros de la conquista (7). Quizás estos últimos procediesen de Montpellier cuando llegaron a Valencia, pero sin duda no fueron los antepasados del Giner Rabassa que participó en el Compromiso de Caspe. Lo cierto es que la rama de los Rabassa a la que nos referimos no eran caballeros cuando llegaron a Valencia. Todo lo contrario, eran notarios y constituyen la ascendencia del mencionado Giner Rabassa de principios del XV.

Indudablemente la lista nominal de los Rabassa es mucho más amplia, pero no poseemos datos para establecer grado de parentesco o filiación alguna entre los integrantes del apellido. Partimos pues de Giner Rabassa, notario de Valencia en 1288, quien él mismo o un hijo con el mismo nombre emite documentos a lo largo del tiempo que resta del siglo XIII. A principios del siglo XIV, sigue apareciendo como notario (8). Este personaje tendría representación política en el municipio, ya que en 1307 y 1311 Giner Rabassa figura en la nómina de ciudadanos que ejercen de consejeros municipales por la parroquia de San Martín (9). En esta misma época otros Rabassa con la misma profesión, quizás familiares próximos, también ocupan puestos en él. Estos son: Nicolau, conseller de ciutadans por la parroquia de Santa Cruz en 1306, y Pere conseller d'oficis i mesters por el oficio de notarios en 1309. Con posterioridad, Arnau es designado dos veces -en 1364 y 1379-como consejero de ciudadanos por la parroquia de San Bartolomé.

\section{PERSONAJES DEL LINAJE}

Si Giner Rabassa, notario, llegó a Valencia en 1238 contando al menos con veinticinco años — pues ésta constituye la edad mínima para poner en práctica su profesión- en 1288 poseería setenta y cinco, y en 1300 contaría con unos ochenta y siete aproximadamente. Esta avanzada edad es la que tendría al fallecer, pues de ese año data la última referencia que poseemos sobre su existencia. Esta es la razón por la que quizás entre Giner Rabassa, 
notario, y el siguiente miembro del linaje - Giner Rabassa major - exista otro personaje intermedio a la hora de componer la sucesisón directa. Es decir, cabe la posibilidad de que entre 1238 y 1300 existieran dos notarios con el mismo nombre (padre e hijo respectivamente).

Sea como fuere el siguiente Giner Rabassa claramente documentado es I'honrat micer Giner Rabassa, major de dies, licenciat en leys, habitador de València. Su primera referencia documental pertenece al año 1325, por lo que se sitúa en el estadio generacional inmediatamente posterior al de Giner Rabassa, notario. Si en esa fecha contaba veinticinco años - los necesarios para lograr la mayoría de edad y acceder a las magistraturas ciudadanas-, viviría durante ochenta y dos años, pues la primera referencia como difunto pertenece a 1382. Este personaje casó con Isabel Caldero, que pertenecía a la pequeña nobleza valenciana (10). Sus hijos fueron:

- La noble dona Joana Rabassa, esposa de Pere de Centelles hasta 1398, año en que éste fallecería (11). Poco después, en 1402, contraerá nuevas nupcias con mossen Francesc de Perellós, a quien también sobreviviría, ya que este falleció en la batalla de Giger, durante la campaña de Mallorca realizada en 1417 (12). La última noticia que poseemos sobre esta dama pertenece a 1419, cuando por primera vez interrumpe una actividad que venía desarrollando regularmente desde 1399: el 27 de septiembre percibe los ultimos ochocientos ocho sueldos, que el consell le paga anualmente en concepto de renta por los censales que posee cargados sobre el municipio (13).

- Hermano de Joana Rabassa e hijo de Giner Rabassa, major, era Giner Rabassa menor, licenciat en leys y habitador de la ciudad (14). Su presencia es detectable desde poco antes de que acaeciese la muerte de su padre. En 1381, Giner Rabassa, major, cobra setecientos cincuenta sueldos de renta en concepto de intereses por los censales que posee cargados sobre el municipio. Esa es la primera vez que desde 1368 ha alterado su cota de renta anual (15). Nada se especifica sobre si el beneficiado ha sido Giner Rabassa major o menor, pero lo cierto es que Giner Rabassa major cobró por última vez una renta en 1382 (16). Por el contrario, ese mismo año su hijo Giner Rabassa menor empieza a cobrar regularmente los intereses devengados de la municipalidad (17).

Por otro lado, Giner Rabassa menor aparece consignado por primera vez como casado en 1389. Su esposa es Maria Ferrandez de Tarazona, la cual está documentada como viuda desde 1413 (18). 
Fuera de este contexto sucesorio debemos situar un miembro más de la familia, sin que conozcamos su parentesco exacto con el resto del linaje, aunque todo hace pensar que fuese hermana de Giner Rabassa major. Ella es Toda Perez Rabassa, viuda de l'honrat Jofre de Ripoll, doncel habitador de Valencia, desde 1405, aunque parece que su esposo habría fallecido con bastante anterioridad. Hijo y heredero de este matrimonio fue l'honorable mossen Joan de Ripoll, cavaller (19).

\section{VÍNCULOS MATRIMONIALES}

I. Giner Rabassa major, licenciado en leyes, estuvo casado con Isabel Caldero, según se deduce de la percepción de derechos que el heredero universal de ésta realizaba en 1384 (su hermano Pere, caballero y habitador de Valencia) (20).

II. El primer matrimonio de Joana Rabassa se realizó con Pere de Centelles, señor de Nules, de cuya unión nacería Aldonza de Centelles quien a su vez -en torno a 1436 - casaría con Francesc de Bellvis (21). Tenemos noticia de que el marido había fallecido ya en el año 1400 porque es la primera vez que su esposa es consignada como viuda, pero lo cierto es que murió en 1398, a lo largo de un enfrentamiento contra el bando de los Soler (22). Su muerte provocaría las ansias de venganza del linaje, especialmente de su hermano Gilabert, según los documentos que aporta A. Rubio en su de la Valencia bajomedieval (23). Por tanto, este Pere Centelles es hijo de Pere de Centelles, señor de Nules y Ramoneta de Riusec.

El linaje de los Centelles estaba afincado en el reino de Valencia desde la misma conquista. Su participación en las distintas campañas de conquista les reportó heredamientos en Xàtiva, Orihuela y Murcia (24). En el siglo XIII los Centelles no eran nobles en un sentido estricto, sino unos simples caballeros que acudian con sus armas a la hueste convocada por el rey (25). No obstante, desde la participación de estos caballeros en la conquista hasta mediados del siglo XV, el linaje compondrá una serie de ramificaciones en su descendencia, alcanzando un importante número de miembros, según podemos comprobar en el trabajo de J. Caruana (26). No obstante, tampoco hay que olvidar que el linaje sólo empieza a estar prolijamente documentado desde los primeros decenios del siglo XV. Esta es la razón por la que nos parece conveniente apuntar una serie datos sobre los Centelles, coetáneos a la época, intentando describir sumariamente el rango e importancia del linaje. 
A principios del siglo XIV, Gilabert de Centelles casó con Blanca de Moncada, hija del noble Ramon de Moncada. La boda se celebraba a condición de que el futuro marido comprase a su suegro el castillo y el término de Nules por doscientos cincuenta mil sueldos. El término de éste comprendía los lugares de Moncofa, l'Alcúdia, Mascarell, Aqua Viva y la propia villa de Nules, y además todos los derechos y rentas derivadas del castillo, las tierras cultivadas, los hombres, los prados, los pastos, la pesca, el agua, e incluso sobre la mitad del diezmo recaudado (27).

Uno de los hijos de este matrimonio sería el heredero universal: Gilabert de Centelles, que casaría en 1333 con Toda de Vilanova. Poco después, en 1357, compra al rey el lugar de Xilxes por ciento cuarenta mil sueldos, y en 1364 también compra a la monarquía la alquería de Llombay en Burriana. También intentaría apropiarse, aunque sin suerte, de Vila-real (28). Hijo y heredero del matrimonio sería Pere Centelles, que casó con Ramoneta de Riusec, heredera de Oliva y el Rebollet. Ramon de Riusec y Diez casado con Castellana de Vilanova, muere sin descendencia dejando a Ramoneta - su hermana- ambos señoríos, a través de la cual entroncarán con los Centelles en 1387 puesto que lo heredarla Gilabert, hijo de Ramoneta y Pere (29). Este Gilabert Centelles es el que intentaba vengar a su difunto hermano, Pere Centelles esposo de Joana Rabassa, desde 1398.

En 1448, Alfonso $V$ hizo a los Centelles condes de Oliva en recompensa a la multitud de servicios militares que le habian prestado, especialmente en las campañas de Nápoles, pero el linaje formaba parte del grupo de los nobles, es decir de los barones del reino de Valencia, con mucha anterioridad, tanto en Nules y Oliva como del valle de Ayora (30).

Si algo sobresale del linaje Centelles es su tradicional apego a las armas en la más rancia tradición aristocrática y medieval. Junto a Pedro IV combatieron a los unionistas valencianos (1349), a los genoveses (1352) y a los castellanos (1356); firmaron paces con los reyes de Fez y Granada (1357); rechazaron la invasión de tropas francesas en Cataluña, ayudando a Juan I (1390); navegaron en las naves de Martín el Humano para sofocar las revueltas de Sicilia en los primeros años del siglo XV; y con Alfonso $V$ asistieron a las campañas italianas, siendo presos con el rey en Ponza (1435), etc ... (31).

El triunfo de Fernando de Antequera en la batalla de Sagunto y la posterior elección como monarca de la Corona de Aragón supuso el encumbramiento definitivo de los Centelles. Con anterioridad, el linaje había formado parte del cuerpo de consejeros de la monarquía: Gilalabert fue consejero de Pedro IV a principios de su reinado para ser nombrado después su Mayordo. 
mo; Eimeric fue uno de los más importantes consejeros de Juan I; mientras que Pere sería Camarero de Martín el Humano (32). Con la llegada al trono de la dinastía Trastámara, Bernat Centelles será nombrado Mariscal de la corona, siendo acompañado por su hermano Gilabert como consejero de Fernando I y de Alfonso $V$ en los primeros años de sus respectivos reinados. Bernat también sería nombrado virrey de Cerdeña y conde Gozia, falleciendo en 1433 (33). Cristobal Centelles, señor de Nules y Almedijar, sería nombrado en 1422 marqués de Quirra, en Cerdeña (34).

La actividad militar al servicio de la corona así como la presencia política - de forma continuada - en el cuerpo deliberativo de la máxima instancia de gobierno (el consejo real) canalizaban las atenciones de los Centelles. Por el contrario, no ejercieron ningún puesto de gobierno en la ciudad salvo alguno de caracter militar o protocolario (35). En este sentido, debemos recordar que sólo tenían acceso a las magistraturas municipales los miembros de la nobleza menor -los cavallers y generosos- por tanto los Centelles siendo barones, marqueses y condes, formando parte de la más alta jerarquía nobiliaria del reino carecían de derecho alguno para acceder al gobierno ciudadano (36). De todos modos, eso no suponía una desinhibición de intereses respecto a una esfera de poder menor como lo era el municipio. Todo lo contrario, las banderías que capitanearon los Centelles a finales del siglo XIV y principios del siglo XV hacían llegar sus influencias desde la misma corte regia hasta los personajes menos relevantes de la administración ciudadana. La filiación política y la adscripción a un bando era una tendencia de la que muy pocos habitantes de la ciudad quedaban exentos (37).

III. El segundo matrimonio de Joana Rabassa está documentado en 1402 , a los cuatro años de la defunción del primer marido. El nuevo enlace se mantendría hasta principios de 1417, fecha en la que moriría su segundo esposo, Francesc de Perellós. De este matrimonio nacerían Giner Rabassa de Perellós - que iniciaria la línea de los marqueses de Dos Aguas-, Francesc, y Caterina, la cual casaría con Jofre de Blanes, de la casa de los condes de Villanueva (38).

El noble Francesc de Perellós era hijo del matrimonio contraído entre Francesc de Perellós y Constanza de Proxida. Los abuelos de su esposa eran Olfo de Proxida y Estefania Carroz. Del mismo modo, hermanos de él fueron Ramon de Perellós, vizconde de Roda desde 1390; Ponce (esposo de María de Francia, dama de Violante segunda esposa de Juan I); y Brunicsen, esposa de Eimeric de Centelles (39). Su ascendiente paterno, el linaje Perellós, procedía de Cataluña, y según García de Carrafa,su padre fue Francesc de Perellós, destacado consejero de Pedro IV, especialmente en cuestiones de índole militar. 
Los Perellós están documentados en Cataluña desde 1312, momento en que llegaron del Rosellón, lugar en donde estaba ubicada la casa principal. El primer miembro del linaje que pasó al reino de Valencia fue Francesc de Perellós, esposo de Joana Rabassa. No obstante, el linaje participó en todas las campañas militares de la corona, formando parte simultánea mente del consejo real. A comienzos del reinado de Pedro IV, Ramon de Perellós ya era su consejero. Su hijo Francesc (suegro de Joana Rabassa) ya era Mayordomo de la casa de Aragón en 1354; en 1358 ocuparia el cargo de Camarlengo de Pedro IV; en 1366 es Camarero del rey; tras la muerte del monarca pasó a formar parte, como un miembro más del consejo de Juan I, falleciendo en 1399 (40). Este Francesc de Perellós adquirió el rango noble por concesión de Pedro IV en 1366 como recompensa a los numerosos servicios militares prestados, adquiriendo el tituló de vizconde de Roda y señor de Epila. En 1396 será procesado junto a Bernat Metge y el resto de consejeros de Juan I por "greus, enormes e forts prejudicables injusticies contra dret, fur, usatges, constitucions, franqueses, costums, llibertats, privilegis e bons usos dels dits regnes e terres» Es decir, se le acusa de la dilapidación del patrimonio real del difunto monarca. Dos meses después de abrirse el proceso recibe el encargo de la reina María de entrevistarse con Carlos VI de Francia y con el conde de Armagnac para oponerse a las pretensiones que sobre la corona catalano-aragonesa pretende hacer valer el conde de Foix, precisamente el personaje del que había sido acusado de partidario. En 1398 logrará la absolución del rey Martín.

Los Perellós tampoco dejaron de participar en ninguna guerra (41). De todos modos, es de destacar el protagonismo alcanzando por Francesc de Perellós (padre) en el incidente tradicionalmente considerado como desencadenante de la guerra entre Pedro I el Cruel y Pedro IV el Ceremonioso. Francesc era el almirante de la flota, que en ayuda del rey de Francia se dirigía a combatir a los ingleses, cuando en los mares de Sevilla apresaron dos navíos genoveses,cuya carga fue vendida en beneficio del rey aragonés. Este hecho provocaría las represalias del rey castellano contra los mercaderes catalanes de Sevilla (42).

Hijo de este Francesc de Perellós, y hermano de Francesc de Perellós (esposo de Joana Rabassa) fue Ramon de Perellós. Camarero de Juan I que participó en la campaña de expulsión de tropas francesas en el norte de Cataluña, así como en las expediciones que Martín el Humano dirigió en Sicilia y Cerdeña a finales del siglo. También lo encontramos con las empresas italianas de Alfonso $\mathrm{V}$, e incluso en los prolegómenos que condujeron a la conquista de Nápoles (enfrentamiento contra la casa de Anjou en defensa de la 
reina Juana). Estas empresas militares y larga lista de embajadas al servicio de la corona dió lugar a que le fuese concedido el título de vizconde de Perellós en las Cortes de Zaragoza de 1390 (43).

De nuevo volveremos a dejar constancia de que los Perellós - como los Centelles - no ostentaron magistraturas municipales porque tenían imposibilitado su acceso mediante pautas municipales y reales de carácter jurídico. Tan sólo algún puesto militar o alguna embajada protocolaria constituyen su curriculum en la ciudad. Por el contrario, el ámbito en el que desarrollaron sus "carreras políticas» como nobles lo constituía la corte real o las campañas militares. Era allí donde obtenían títulos y promoción política, siempre al servicio de la monarquía. Sólo ocasionalmente se derivaba de ello el nombramiento en algún puesto de gobierno en las instituciones regias, sobre todo las que reunian connotaciones militares $u$ organizaban territorialmente el reino. Nos referimos a la Governació de València (44).

IV. Los Rabassa también emparentaron con el linaje de los Ripoll a través del matrimonio contraído entre Toda Perez Rabassa y Jofre de Ripoll. Las noticias más antiguas de este apellido se remontan a poco después de la conquista, ya que Berenguer Ripoll, escribano, está documentado en Valencia desde 1275 (45). No obstante, a mediados del siglo XIV existen dos ramas claramente diferenciadas en su estatuto jurídico, unos son ciudadanos y otros son caballeros. Los ciudadanos - que seguían profesando la notaría - y los caballeros participaron de forma diferente en el gobierno municipal en sus distintas formas de representación socio-instituticional. Sólo nos ocuparemos de la rama del linaje que emparentó con los Rabassa, aunque ambas descendían de un mismo tronco común en la primera mitad del siglo XIV (46).

Jofre de Ripoll, difunto en 1405, habría casado hacía bastante tiempo con Toda Perez Rabassa, porque el único miembro conocido del linaje con ese mismo nombre debía de haber alcanzado la mayoría de edad en 1369 (47). A pesar de que Jofre de Ripoll no desarrolló personalmente una carrera política en la ciudad, fue nominado ese mismo año y el siguiente como candidato a las elecciones de Jurados por los caballeros, en las parroquias de Santa María y de San Salvador respectivamente. No llegaría a ostentar ningún puesto de gobierno, y tras él iniciarían sucesivamente su carrera Nicolau, Berenguer, Joan y Manuel.

El linaje de los Ripoll ocupó un número de cargos en el municipio bastante elevado entre 1356 y 1419, a pesar de que el número de magistraturas a las que tenían acceso los cavallers i generosos era bastante más reducida 
que la de los ciudadanos. En sesenta y tres años cinco miembros del linaje ocuparon más de veinte cargos entre los puestos «políticos» del municipio (48).

Con anterioridad a Jofre de Ripoll, la presencia del linaje en el municipio estuvo materializada con Berenguer,quien fue electo como Jurado en 1323, 1325, 1337, 1339 y 1350; en 1357 fue conseller de cavallers; además en 1336 ejerció la magistratura de Justicia Criminal; y participaría en la guerra contra Castilla, lo que sin duda fue mérito suficiente para que en 1372 obtuviese el puesto de camarlengo en la corte regia (49). Este Berenguer de Ripoll, caballero, fue un personaje que gozó de especial prestigio y consideración en la ciudad, pues fue él quien compró en 1356 el primer censal emitido por el municipio de Valencia (50). No obstante, debemos plantear un problema: este Berenguer de Ripoll ¿ nació caballero ? o por el contrario ¿ era un ciudadano que, descendiente de la rama de los Ripoll dedicados a la notaría, logró acceder a la caballería? Hasta 1329 los caballeros no tuvieron reglamentado jurídicamente su acceso a los cargos de Jurados y, sin embargo, Berenguer Ripoll ocupó esa magistratura en 1323 y 1325. Las cuatro plazas de Jurados existentes desde 1245 hasta la fecha citada tuvieron que estar regentados por ciudadanos, según estipulaban fueros y privilegios (51). Los Ripoll se habían ennoblecido a finales del siglo XIV.

Este Berenguer de Ripoll desaparece de la vida pública aproximadamente en la década de los setenta del siglo XIV, quedando enmarcada entre 1323 y 1372 , coincidiendo con el momento en que Jofre se presentaba por primera vez a unas elecciones municipales (1369 y 1370). Tras él vendría Nicolau Ripoll, habitador de Valencia, electo Jurado por los caballeros en 1388 desde la parroquia de San Salvador.

El segundo Berenguer de Ripoll desarrollaría su carrera política en la ciudad entre 1379 y 1388, aunque tildado con los apelativos de mossen y de cavaller desde el primer momento. Ostentaría las siguientes magistraturas municipales: Jurado en 1379 (por la parroquia de Santa María), en 1380 y 1387 , Justicia Criminal en 1388, y capitán de galeras de la ciudad en 1385.

Joan de Ripoll, doncel en 1388 y armado caballero ya en 1408, desarrolló su carrera política en el municipio entre 1389 y 1412 . Entre las magistraturas ostentadas destacan: conseller de cavallers en 1389, 1398, 1406 y 1412; en 1398 y 1404 desempeñó el cargo de Inquiridor contra los oficiales de la ciutat; en 1408 sería embajador de la ciudad a Castilla; en 1409 ejercería el cargo de Justicia Civil; y en 1411 fue electo como Jurado por la parroquia de Santo Tomás, haciendo simultáneamente las veces de juez en el tribunal de apelaciones de los emprius o aprovechamientos comunales del término 
de la ciudad. No obstante, de éste personaje destaca el papel desarrollado en la defensa de la ciudad cuando ésta estuvo amenazada, en 1411, por las tropas de Fernando de Antequera y los partidarios del linaje Centelles. Joan de Ripoll, cavaller, electo como inspector de las defensas - torres y murallasorganizaba y capitaneaba las milicias parroquiales e incluso aportó tres caballos armados para la caballería de la ciudad. Joan era considerado en estos momentos por el Consell como una de las «persones notables e de be, havents afecció al ben avenir de la ciutat» (52).

Esta misma opción política fue la mantenida por Manuel de Ripoll, doncel en 1392 y cavaller en 1408. Si bien accedió a varios puestos de gobierno entre 1392 y 1409 (conseller de cavallers en 1391 y 1409, Justicia Civil en 1392, e Inquisidor contra los oficiales de la ciudad en 1407) aparece retirado de la esfera del poder municipal incluso antes del Interregno (53). Sea como fuere su apoyo fue incondicional a favor de los partidarios del linaje Vilaragut a lo largo de todos los episodios de la lucha de bandos a finales del siglo XIV.

Es decir, los Ripoll caballeros -al menos con toda seguidad desde el primer tercio del siglo XIV - han estado representados en el gobierno ciudadano a través de los distintos personajes del linaje, en una verdadera sucesión cronológica y con una regularidad apreciable, a pesar de los imperativos que imponía el azar mediante el sistema utilizado para la provisión de magistraturas en la ciudad.

V. En último lugar queda hacer referencia al matrimonio del mismo Giner Rabassa, menor, quien aparece casado ya en 1389 con la honrada dona Maria Ferrandiz. El apelativo utilizado para designarla nos indica su filiación nobiliaria ya que los Ferrandiz o Ferrandez están presentes en el reino de Valencia con dos líneas de sucesión completamente diferentes. Ambos linajes tienen rango nobiliario y están poco muy poco documentados a finales del siglo XIV. Una de estas líneas de sucesión es la que emparenta con el arzobispo de Zaragoza, Garcia Ferrandiz de Heredia, asesinado por los Luna en 1411 ante la negativa de éste a colaborar con los partidarios de Jaime de Urgel. Blasco Ferrandiz de Heredia, difunto, y un hijo con el mismo nombre eran señores de Foyos y de Alfandaguella en 1372 (54). La otra línea es la dé los Ferrandiz Munyoz, linaje valenciano que junto a los Diez y Centelles se enfrentaron repetidamente a los Vilaragut. Ni siquiera podemos determinar con certeza a cual de las dos ramas de Ferrandiz pertenecia Maria. No obstante, sí podemos ratificar sus orígenes nobiliarios y la filiación política de su linaje a finales del siglo XIV y principios de la siguiente centuria. Tanto los Ferrandiz de Heredia como los Ferrandiz Munyoz eran destacados enemigos de los partidarios de Jaume d'Urgell en Aragón y en Valencia. Es más, a prin- 
cipios del siglo XV los Ferrandiz de Heredia enlazarían con el linaje de los Diez. Joana, hija de Manuel Diez de Calatayud «lo antich», señor de Andilla, casaría con Joan Ferrandiz (55). Los Diez destacaron en la Valencia del trescientos, según indica Salvador Carreres y Zacarés, por tradicional enfrentamiento - junto a los Centelles- contra los Vilaragut.

\section{ESTATUTO SOCIO-PROFESIONAL Y PROYECCIÓN POLÍTICA}

La exposición precedente nos mostraba una clara tendencia: los Rabassa no sólo emparentaron con linajes de la nobleza media y menor de Valencia - caso de los Caldero o de los Ripoll- sino con los más altos dignatarios de la aristocracia, con los barones del reino, como lo fueron los Centelles y los Perellós.

En sus orígenes los Rabassa, especialmente el notario llamado Giner, no fueron más que unos repobladores que, en el caso concreto de este personaje, trabajaba en la administración regia. A lo largo del primer tercio del siglo otros personajes apellidados del mismo modo, e incluso este mismo Giner, ocupan alguna vez un puesto de consejero de las parroquias en el Consell como un ciutadà. Sin embargo, el rango de todos ellos - a pesar de ser ciudadanos- dista mucho de estar a la altura del grupo de ciutadans honrats que se perpetuan en los puestos políticos en la administración municipal.

En la siguiente generación Giner Rabassa major, sucesor del notario anterior, ha adquirido estudios universitarios, apareciendo como abogado o licenciat en leys, pero también ha variado el apelativo que lo intitula: los Rabassa han dejado de ser ciutadans para adquirir el nuevo rango de generós (56). Es decir, ha obtenido el status correspondiente al escalafón de la nobleza menor, y de esta forma contrae matrimonio en el nivel social recién adquirido, casando con Isabel Caldero.

En efecto, en la tercera generación Giner Rabassa, pus jove o menor, sigue practicando la misma actividad profesional de su padre, pero en 1378 es consignado simultáneamente como licenciat en leys y generoso (57). La carrera ascendente del linaje continúa porque, en 1391, Giner Rabassa menor ha sido armado caballero. Debemos pensar que este hecho obedece a los servicios prestados en la administración regia como jurista. Desde ese momento Giner Rabassa será intitulado simultáneamente como mossen, micer y cavaller. Por último, en 1392 la promoción del linaje continúa, aunque ahora se ciñe al ámbito profesional:en esa fecha Giner Rabassa ya ha alcanzado el grado de doctor en leys (57). 
El status socio-profesional del linaje alcanza su cénit en la tercera generación con Giner Rabassa menor. Del mismo modo, los matrimonios practicados por su hermana Joana Rabassa dejan entrever el rango del linaje: los dos consortes - primero Pere de Centelles y segundo Francesc de Perellós pertenecian al estatuto de mayor rango nobiliario, porque eran barones del reino. Por tanto, el prestigio socio-económico de los Rabassa debía ser lo suficientemente importante para que posibilitase estos enlaces con los nobles del reino. En este sentido, el prestigio de Giner como jurisconsulto debió de ser extraordinario, ya que estando vinculado a la parroquia de San Pedro durante su vida, cuarenta años después -en 1453 - todavía se llamaba por su nombre la plaza donde estuvo ubicado su alberch (58).

Todo parece indicar que Giner menor no tuviera descendencia porque en adelante los Rabassa quedan completamente vinculados a los Perellós (59). El segundo matrimonio de Joana dará lugar a la formación del vínculo de los Rabassa de Perellós. El apellido del vínculo creado nos revela sintomáticamente la condición de los dos linajes enlazados.A pesar de que que los Perellós son nobles y de que éste es el apellido del marido, en adelante el nuevo linaje se denominará Rabasa de Perellós. Es decir, no sólo no se pierde el apellido de la esposa sino que incluso se antepone al del marido noble. La formación de una descendencia con estas características, a partir del nudo matrimonial Rabassa-Perellós, es lo suficientemente revelador para indicarnos el status social del linaje Rabassa a principios del siglo XV (60).

El primogénito y heredero del vínculo fue Giner Rabassa de Perellós, señor de Benetuser y de Dos Aguas, que como noble participaría en las campañas italianas de Alfonso $V$, siendo preso en Ponza. En 1699, el linaje adquirirá el rango de marqueses con Giner Rabassa de Perellós y Pardo de la Casta.Hermano de éste sería Ramon, maestro de la Orden de San Juan de Jerusalén. A lo largo de los siglos XVII y XVIII los Rabassa de Perellós emparentarían con la nobleza valenciana de mayor alcurnia como fueron los condes de Albatera, condes de Rocabertí, etc. Su descendencia se extinguiría a mediados del siglo pasado.

Cuando iniciamos la investigación no teníamos ni idea de que los Rabassa, especialmente major y menor pertenecían al estamento militar o a la mà major. Nada de ello se indicaba en una bibliografía que tan sólo se limitaba a indicar que Giner Rabassa menor, comisionado de la ciudad y reino en el Compromiso de Caspe, sólo era un simple jurista.

No obstante, debemos plantearnos ¿cuándo comenzaron a ennoblecerse los Rabassa? Ciudadanos a principios del XIV, Giner major tuvo un curri- 
culum politico no demasiado abultado, aunque entre otras magistraturas municipales ostentó en 1325 uno de los cuatro puestos de Jurado, y en 1326, el de Mostassaf de la ciudad. Ambos cargos sólo podían ser ejercidos por ciudadanos hasta 1329. Sin embargo, la primera referencia como generoso o habitador pertenece a 1364. Por tanto, en algún momento de esos cuarenta y dos años de intermedio alcanzaron el nuevo rango. En adelante, todos los puestos políticos que desempeñen en la administración municipal estarán adscritos a los que tiene reservado en exclusiva la mano mayor.

En 1370, Giner Rabassa major percibió de las arcas del común ciudadano una pequeña cantidad de dinero en concepto de «expropiación» de cuatro olmos de su propiedad que le han sido talados por el municipio (61). La noticia, en principio es un tanto anécdotica, pero nos advierte de la existencia de cierta propiedad rural en manos del linaje. En efecto, porque en $1369 \mathrm{Gi}$ ner compró a Pedro IV el lugar de Alcacer - situado en la huerta de Valenciapor ochenta mil sueldos (62). Los Rabassa convertidos en señores de una pequeña entidad territorial reunían las condiciones necesarias para transformarse en un home de paratge, en un generoso (63).Además Pedro IV dotaría a Giner del estatuto jurídico propio de la nobleza menor en recompensa a los servicios prestados como consejero de la corona.

El currículum político de los Rabassa no es demasiado abrumador. El padre, aunque abogado, fue Jurado de la ciudad en 1325, 1333, 1357, y 1371; Mostassaf en 1326; representante de la ciudad en las Cortes de 1342 y 1349. Entre los cargos honoríficos que éste ostentó - que nos revelan parcialmente su rango social- debemos de destacar que llevó uno de los bordones del palio de Pedro IV, cuando en 1336 vino a ciudad para jurar los fueros y privilegios del reino. En 1359 es designado como uno de los síndicos de ciudad para ocuparse de los problemas de la guerra contra Castilla. En 1364 es electo síndico de la ciudad para asistir a las Cortes de Monzón. Entre 1363 y 1364 es consejero del brazo eclesiástico en la Generalidad valenciana. Además fue consejero de Pedro IV desde 1358.

Por el contrario, la carrera del hijo es mucho más reducida empezando a detectarse en 1372, cuando es nombrado por el Consell como oidor de comptes de la ciudad. En 1378 es electo para ocupar una de las dos plazas de Jurados -en la parroquia de Santa María - reservadas al estamento militar, porque aunque sea abogado, también es generoso. Del mismo modo, ocupará en 1379, 1380 y 1407 uno de los seis puestos de consellers de cavallers i generosos. Fuera del ámbito municipal, en la corte regia, también desempeñó importantes cargos entre los que destacaba el de tesorero de Juan l, según indica Pere Maria Orts i Bosch. En 1392 lleva uno de los bordones del 
palio que cubre a reina cuando visita la ciudad. El rango y la importancia de los personajes que realizaban tales funciones en este tipo de ceremonias queda fuera de todo comentario (64).

No obstante, no debemos extrañarnos del relativamente escaso currículum político de ambos personajes, ya que los Rabassa aunque patricios fueron juristas. Su carrera, por tanto, no será exclusivamente política sino que estará enmarcada dentro de las instituciones de gobierno ciudadanas en otra categoría, la del grupo de especialistas en leyes que posee la ciudad.

En este sentido, no debemos de olvidar su actividad profesional. Giner Rabassa major publicaría varias obras versadas sobre el derecho foral valenciano, entre las que destacan el Comentarium in aliquas leges, las Notae super foris Regni Valentie, y un largo comentario al fuero único rúbrica cinco de las Cortes de 1358, dedicado al análisis de la potestad del testador para poder dejar sus bienes libremente a cualquier persona, excepto a los generosos. Su hijo Giner menor seguirá la tradición familiar y en 1402 ya es autor del Comentarii in foros valentinos. Es decir, ambos figuran entre los glosadores de los fueros valencianos (65).

Independientemente de esta actividad profesional e intelectual, Giner Rabassa major sería uno de los Advocats pensionats de la ciudad desde 1351, cargo que ejercería -durante más de treinta años- hasta el mismo momento de su muerte, acaecida en torno a 1382 (66). Con anterioridad a esa fecha fue uno de los abogados adscritos a la Bailía como asesor en materia legal (67).

La ciudad mantenía cuatro abogados pensionados, cuyo nombramiento hacía el Mostassaf, aunque la toma de posesión del cargo se realizaba ante los Jurados. Como indica el mismo Eliseo Vidal Beltrán, las plazas eran cubiertas de una manera un tanto oscura, hasta que en 1389 se acuerda otorgarlas efectuando un sorteo de redolins, en el que participan los seis juristas más reputados de la ciudad. La elección se realizará en la vigilia de San Miguel, inmediatamente después de la elección del Mostassaf, y el cargo será adjudicado por un año, estipulándose la imposibilidad de que una misma persona vuelva a ser electa de nuevo para esa magistratura hasta que hayan transcurrido al menos de tres años (68). Pero la realidad electoral era otra, completamente distinta. Lo usual es que la elección se dejara en manos de los Jurados, quienes efectuaban el nombramiento para cubrir la plaza vacante entre las personas que estimaban idóneas. Los consejos prestados por el resto de abogados pensionados y los consellers eran tenidos en cuenta antes de realizar la elección, pero el poder decisorio radicaba en los Jurados. La duración del cargo no era anual, como hemos podido comprobar -ya 
que Giner Rabassa ejerció el puesto durante más de treinta años consecutivos sino que estaba sometida a la voluntad del Consell (69).

No debemos pensar que el cargo de Advocat pensionat era un puesto eminentemente "administrativo", sino que también reviste características politicas. Su papel consiste en asesorar en materia legal el «comportamiento político» de los Jurados, tanto en la actividad ordenancista que éstos desarrollan para organizar la vida socio-económica de la ciudad, como en la confección de borradores de fueros, que el mismo brazo real presentará en las Cortes solicitando su aprobación. También correspondía a los abogados pensionados por la ciudad el estudio de la legislación emitida por la cancillería real, bajo la forma de privilegios, provisiones o sentencias, comprobando si ésta individualmente se atenía al contenido del conjunto de las libertades forales concedidas con anterioridad, por el mismo monarca o sus predecesores. Indiscutiblemente, los abogados también se ocupaban de la defensa y/o acusación en los pleitos que la ciudad mantenía respecto a otras personas físicas o jurídicas. Es decir, gran parte de la tarea de los abogados radicaba en la interpretación-aplicación de la legislación foral, y en la preparación de los nuevos fueros que se pretendían poner en vigor. Esta es la razón por la que no podemos considerar su actividad como exclusivamente administrativa, porque el contenido político de ella se pone de manifiesto desde el momento en que están al servicio de los Jurados de la ciudad (70). En este sentido, debemos de recordar el papel desempeñado por los abogados a lo largo de 1347-1348 cuando los repetidos contrafueros de Pedro IV - nacidos del creciente autoritarismo monárquico- mermaron las libertades de la ciudad y reino de Valencia (71). Del mismo modo, tampoco podemos olvidar que el papel político asignado a los abogados de la ciudad por Alfonso $\mathrm{V}$, en la reforma de la organización de la estructura institucional del municipio, realizada en 1418 , sin duda alguna tenía precedentes. El nacimiento del consell secret como órgano decisorio, superpuesto institucionalmente al resto de consejeros y magistraturas municipales consolidaba definitivamente las atribuciones políticas de los abogados de la ciudad (72).

Pero Giner Rabassa major también ocupó otros cargos en el municipio,que podría caracterizar como eminentemente técnicos, acordes con el desempeño de su profesión. En 1345 es electo para ocupar una de las seis plazas de consellers de juristes (73). Con anterioridad, en 1337, fue designado por el Consell como uno de los cuatro Examinadors de notaris. Este cargo era provisto anualmente en la misma proporción entre los licenciados/doctores en leyes y los notarios, aunque en ocasiones dos Jurados participaban también en el tribunal. Su misión consistía en someter a examen a los aspirantes 
al desempeño de este arte en la ciudad (74). Del mismo modo, Giner fue electo en 1342 entre un conjunto de veinte prohombres, que Valencia envió a Pedro IV para integrarse en una asamblea parlamentaria reunida en Barcelona, en la que sus integrantes debían de asesorar al monarca sobre la suerte de Jaime III de Mallorca (75).

Por el contrario, Giner Rabassa menor, que asistió al Compromiso de Caspe en 1412, ejerció simultáneamente de asesor del Gobernador -al menos desde 1391-, como comisario regio en determinados asuntos, y como juez o arbitro en los numerosos procesos de la ciudad (76).

No obstante, la carrera jurídica y política del linaje prácticamente finalizó el cinco de mayo de 1412, cuando Giner menor fue declarado impedido e inhábil como elector del futuro monarca de la Corona de Aragón (77). No se ha logrado esclarecer si su enfermedad fue fingida (para evitarse el cargo de conciencia de la elección), si tenía motivaciones de índole política (la enfermedad fue alegada por su yerno Francesc de Perellós, partidario de los Centelles y de Fernando de Antequera), o si en realidad padeció una verdadera enfermedad. Las tres posibilidades historiográficas se han sopesado por distintos autores e incluso se ha llegado a diagnosticar la enfermedad «delirio onírico» (78). Sea como fuere lo cierto es que los hermanos Ferrer designarian como sustituto a Pere Bertran, doctor en decrets. No obstante, éste votaría en blanco en la elección de Caspe. La filiación trastamarista de San Vicente y de Bonifacio Ferrer hacen sospechar la incompatibilidad política con Giner Rabassa. De todos modos, Giner menor, ya de avanzada edad fallecería en 1413 sin dejar descendencia masculina, pues el apellido Rabassa -individualizado- desaparece por completo de la documentación municipal.

En conclusión, el linaje Rabassa encuadrado en un principio en los niveles inferiores de la administración como escribanos y notarios, forman parte del aparato técnico de ésta, de los especialistas de la pluma. En una segunda generación se convierten en especialistas del derecho, en letrados capaces de conducir las decisiones políticas de los Jurados de la ciudad por el intrincado mundo de las formulaciones legales (79). Giner Rabassa, major, no aprendió la profesión mediante un contrato de aprendizaje doméstico (así lo haría su padre para introducirse en el arte de la notaría), sino que estudió en la universidad, convirtiéndose en licenciado en leyes. En la tercera generación Giner Rabassa, menor, superara incluso el rango académico de su padre, logrando el doctorado. De modo paralelo, debemos de destacar que conforme los Rabassa se promocionan dentro de su profesión,también ascienden en la escala social, consiguiendo en cada generación subir un nuevo 
peldaño. En tres generaciones los Rabassa pasan de ser unos ciutadans de rango menor, a generosos en la siguiente, para convertirse en cavallers en la tercera (80). El estatuto jurídico conseguido en cada momento posibilitaba unos enlaces matrimoniales no sólo acordes con su posición, sino incluso superiores. Los Rabassa casaban con nobles a finales del siglo XIV, quizás debido al prestigio profesional y político del linaje, pero también por el tamaño de su patrimonio y la cuantía de sus rentas, las cuales todavía hoy son en gran parte desconocidas. 



\section{NOTAS}

(1) Este artículo ha sido extractado de uno de los capítulos de nuestra tesis donde se presentaban varios linajes, tratando de delimitar los rasgos más característicos del patriciado urbano. No obstante, aquí nos ceñiremos tan sólo a mostrar su estrategia matrimonial, su carrera política y la evolución de su estatuto social. Cfr. Gobierno politico y luchas sociales. Estrategias de poder del patriciado urbano. La ciudad de Valencia (1356-1419). Tesis doctoral inédita dirigida por Paulino Iradiel Murugarren, catedrático del Departamento de Historia Medieval de la Universidad de Valencia. 2 vols., Valencia, 1989.

(2) Cfr. Escolano, Gaspar: Décadas de la historia de Valencia. Edición facsímil de la Universidad de Valencia en base a la edición de 1610. Valencia, 1970. Col. 580 n. ${ }^{\circ} 5$.

(3) Cfr. Garcia de Carrafa, A. y A.: El solar catalán, valenciano y balear San Sebastián, 1968. Vol. IV, p. 1-2.

(4) Sobre la participación de los Rabasa en estas campañas y sobre las tierras que obtuvieron en concepto de recompensa Cfr. Décadas... Op. cit. de Gaspar Escolano, col. 320 n. ${ }^{\circ} 20$.

(5) Cfr. Idem, col. 320 n. ${ }^{\circ} 20$; y también García de Carrafa A. y A. Op. cit. vol. IV p. 1-2.

(6) Existe un número importante de personas que apellidándose Rabassa ejercen esta profesión a finales del siglo XIII valenciano: Pedro III ordena al Justicia y al Baile de Valencia que, en 1281, Jover Rabassa y Guillem Vernet den cuenta a Vidal y David Astruch de las escrituras existentes en las notarías de la ciudad. Cfr. Martínez Ferrando, Jesús Ernesto: Catálogo de la documentación relativa al antiguo reino de Valencia existente en los registros de la Cancillería Real. II. Pedro el Grande Madrid, 1934, doc. n. ${ }^{\circ} 1335$, p. 285, otorgado en Valencia el 15 de junio de 1281.

También tenemos noticias coetáneas de Guillem Rabassa, quien es asegurado ante la corte del Justicia - en bienes y persona - por el pleito que mantiene contra Jafuda Ala. zar, judio. Cfr. ldem, doc. n. ${ }^{\circ} 2301$ en p. 490, otorgado en Barcelona el 22 de octubre de 1285.

Por último, debemos mencionar una serie de documentos privados expedidos por Giner Rabassa, notario de Valencia desde 1288, y que aparecen citados en la obra de Teixidor, José O. P.: Capillas y sepulturas del real convento de Predicadores de Valencia. Introducción y notas por el barón de San Petrillo, Valencia, 1949, tomo I, p. 174; tomo III p. 90 y 190. El documento expedido en época más temprana está datado en Valencia el 23 de agosto de 1288.

Este dato nos lo ha proporcionado el texto de Pere Maria Orts y Bosch en la Enciclopedia de la región valenciana (Valencia, 1973) sin que podamos saber de donde procede, ya que carece de referencia explícita. Hemos de suponer que el término Curia se identifica con el de Consell y no con la institución que supuso el precedente de la creación del Justicia de Valencia, desaparecida en torno a 1250-1251.

(7) Cfr. Trovas de mossen Jaume Febrer que tratan de los conquistadores de Valencia. Edición de Joaquín Mir Bover, Valencia, Imprenta de José Gelabert, 1848. Trova n. ${ }^{\circ} 417$ p. 225 , donde se indica que los Rabassa, caballeros, participaron en la conquista de Mallorca y 
de Valencia. No obstante, también lo hicieron bastantes personas con ese mismo apellido -entre ellas los notarios referidos - sin que pueda asegurarse que la descendencia nobiliaria proceda del linaje de caballeros y no del de los notarios.

(8) Una relación más o menos continuada de los documentos emitidos por Giner Rabassa, notario, padre y/o hijo puede verse en Olmos y Canalda, Elías: Inventario de los pergaminos del archivo catedral de Valencia, Valencia, 1961, en especial los documentos datados en Valencia n. ${ }^{\circ} 465$ (1272, octubre 16), n. ${ }^{\circ} 495$ (1274, junio 24), n. ${ }^{\circ} 584$ (1279, noviembre 21), n. ${ }^{\circ} 665$ (1287, marzo 7), y n. ${ }^{\circ} 904$ (1300, octubre 30).

(9) Cfr. Roca Traver, F.: Ordenaciones municipales de Castellón de la Plana durante la Baja Edad Media. Valencia, 1952, p. 18-20.

(10) En 1325 Giner Rabassa es Jurado de Valencia por lo que debería de poseer al menos la mayoria de edad (25 años). Cfr. la edición realizada por José María Doñate Sebastiá del libro intitulado del Bien y del Mal en Ligarzas 8, Valencia, 1976, p. 9, donde sólo aparecen tres personajes con el cargo de Jurado, ya que la cuarta plaza de Jurado ciudadano está regentada por Giner Rabassa, según indica F. Roca Traver en Ordenaciones municipales... Op. cit. p. 19. Por otro lado, la primera referencia como difunto pertenece a 1382. Cfr. A. M. V. Manuals d'albarans de claveria censals I-12; 1382, abril 22. Por otro lado, todo parece indicar que la fecha de la muerte de Giner major sea la anotada pues sólo se tiene noticia desde 1386 de la existencia de un beneficio instituido por éste - y mantenido por su hijo- en la catedral de Valencia, bajo la invocación de Santa Maria Magdalena. Cfr. A. R. V. Protocolos (Arnau Puig) 2483 (1386, junio 15); y 2484 (1387, febrero 4).

(11) La primera referencia documental que poseemos de Joana Rabassa, viuda de Pere de Centelles, pertenece a 1400. Cfr. A. M. V. Idem, I-22: 1400, agosto 11. No obstante, su marido habría fallecido dos años antes de esa fecha.

(12) La primera referencia documental de Joana Rabassa, viuda de Francesc de Perellós, pertenece a 1417. Cfr. A. M. V. Idem, I-36: 1417, enero 26. Ambos habian contraido matrimonio al menos desde 1402. Cfr. Idem, I-23: 1402, diciembre 29. Sobre su muerte también deja constancia el Dietari del capellà d'Anfós el Magnànim. Introducción, notes i transcripció per Josep Sanchis i Sivera, Valencia, 1932, p. 115, donde se explicita que allí fallecieron entre otros mossen Franci de Pereilós, mossen Pere de Moncada, mossen Lois Vidal y mossen Francesc Marrades.

(13) Cfr. A. M. V. Manuals d'albarans de claveria censals I-39: 1419, septiembre 27

(14) Cfr. Idem, I-12; 1382, abril 22.

(15) Giner Rabassa major percibía regularmente una renta anual de 500 sueldos pagados en dos plazos, por los censales que poseía cargados en el municipio desde 1368.

(16) En 1381, Giner Rabassa cobró 750 sueldos por lo que podemos suponer que al menos 250 sueldos serían cobrados por su hijo Giner Rabassa menor, dado que el 5 de febrero de 1382 Giner Rabassa major fallecería tras percibir sus últimos 500 sueldos de renta. Cfr. A. M. V. Idem, I-12: 1382, febrero 5 (último cobro del padre).

También puede ser interesante constatar que Giner Rabassa, padre, empezó a denominarse major el 5 de mayo de 1373, lo que quizás indicase que su hijo empezaba ya a participar en la vida pública, y que muy posiblemente alcanzase la mayoría de edad, utilizando el nombre de Giner Rabassa menor, o hijo del anterior. Cfr. Idem, I-6.

(17) El primer cobro de intereses por los censales cargados en el municipio por Giner menor está datado el 11 de abril de 1382, cuando percibe 238 sueldos de renta. Cfr. Idem, I-12.

(18) La primera referencia que poseemos como esposo de María Ferrándiz es del 8 de febrero de 1389. Cfr. Idem, I-17. Por el contrario, su esposa aparece consignada como viuda por primera vez el 31 de mayo de 1413. Cfr. Idem, I-33. De la filiación de la esposa desconocemos todo salvo su nombre, al cual accedimos por un documento de carácter privado: la venta de una esclava sarracena de 30 años de edad a Roselló de Bellpuig, cambista de Valencia. ARV. Protocolos 1848 (Arnau Puig): 1409, agosto 1.

(19) Toda Pérez Rabassa es consignada como viuda desde el 15 de junio de 1405, siendo ésta la primera ocasión en que aparece documentada. Suele percibir 300 sueldos de renta anual 
en dos plazos. Cfr. Idem, I-26. Respecto a los Ripoll hablaremos al comentar las estrategias matrimoniales del linaje. Por otro lado, carecemos de cualquier indicación de filiación de $\mathrm{Na}$ Toda, pero lo cierto es que también es la única persona con este apellido documentada desde mediados del siglo XIV. Cabría situarla en el estadio generacional de Giner major a pesar de que los datos que poseemos sobre ella sean más tardíos. Sobre Joan Ripoll Cfr. A. M. V. Idem, I-32: 1411, diciembre 15

(20) Pere Caldero como heredero universal de los bienes de Isabel Caldero y su esposo Giner Rabassa, licenciado en leyes, difuntos, reconoce que Bernat Rosell, presbitero y colector de los censales que poseía Isabel Caldero «in locis, terminis, et terratoris de Alfofar, de Benetuçer, de Pala, de Gabia, e de Cotelles» le ha pagado a cuenta 6.654 sueldos. Cfr. ARV. Protocolos 2437 (Arnau Puig): 1384, enero 28.

Respecto a su familia tan sólo tenemos noticia de que Pere Caldero, padre de Isabel y de Pere Caldero, ejerció de conseller de cavallers en 1356, mientras que su hijo si bien accedió al mismo cargo en 1398, también logró ejercer de Jurado por los caballeros en 1399 (Santa Maria) y 1408 (Santa Catalina).

(21) Cfr. Diago, Francisco O. P.: Apuntamientos para continuar los anales del Reyno de Valencia desde el rey Pedro III hasta Felipe II (Valencia, 1946) vol. I, p. 207.

(22) Cfr. A. M. V. Manuals d'albarans de claveria censals 1-22: 1400, agosto 11. Joana Rabassa aparece consignada como viuda por primera vez en esa fecha. Su esposo, Pere de Centelles, falleció el 11 de junio de 1398 en una lucha de bandos que enfrentó en el Temple a éste y a En Blanes contra mossen Martí de Loriz y Lois de Soler. Cfr. Carreres i Zacarés, Salvador: Notes per a la história dels bandos de València (Valencia, 1930) doc. n. ${ }^{\circ} 10$, letras j, II, m, en p. 46, 49 y 50.

(23) Cfr. Rubio Vela, Agustín: Epistolari de la València medieval Valencia, 1985, doc. $\mathrm{n} .{ }^{\circ} 120$, p. 300-306 (Valencia, 18 de julio de 1399).

(24) Cfr. la crónica de Gaspar Escolano Op. cit. col. 44 n. ${ }^{\circ} 2$ y col. 1164 n. ${ }^{\circ} 2$.

(25) Así podemos comprobarlo cuando el 18 de noviembre de 1273, Bernat Centelles, Ramón de Moncada, Jaume Cervera, Galcerà de Urg, Dalmau de Castelinou, Bernat de Cardona, Galcerà de Pinos, Ramón de Papiol y Ramón de Cardona, son convocados por Jaime 1 el día de Todos los Santos para que se presenten con sus armas y caballos. Cfr. Martínez Ferrando, Jesús Ernesto: Catálogo de la documentación relativa al antiguo reino de Valencia contenida en los registros de Cancillería Rea. I. Jaime I el conquistador Madrid, 1934, doc. 1562.

(26) Cfr. Caruana y Reig, José: Las casonas solariegas. Discurso leído para su ingreso en la Academia de Bellas Artes de San Carlos de Valencia, Valencia, 1940, donde introduce entre otros el árbol genealógico del linaje Centelles. También Cfr. Camarena Mahique, José: «De la historia de Oliva y Rebollet». En Iniciación a la historia de Oliva Valencia, 1985, p. 166; y también A. R. V. Protocolos 312 (Bertrán de Boes) donde el 16 de enero de 1420, Ramoneta de Riusec, viuda de Pere de Centelles, nombra procurador suyo a Guillem Erau, notario

(27) Cfr. Vicent Cavaller, Joan A. y Barceló Torres, M. ${ }^{a}$ del Carmen: La Vilavella. Estudio arqueológico-histórico Valencia, 1977, p. 182-188.

(28) Además debemos de dejar constancia de que también pertenecía a este noble la alquería de Bonretorn, situada en el término de Vila-real (Castellón). Cfr. Ibidem, p. 185.

(29) Cfr. Camarena Mahiques, José Op. cit. p. 165. Los Carroz estaban tradicionalmente heredados en Oliva y Rebollet hasta la extinción del linaje. Sus heredamientos pasarán a los Riusec por vía matrimonial, según anota José Caruana en la genealogía Centelles.

(30) Cfr. Gaspar Escolano Op. cit. col. $160 \mathrm{n} .{ }^{\circ} 7$, pero con anterioridad los Centelles ya formaban parte de los «grandes» títulos del reino. Por ejemplo, Cfr. A. R. V. Protocolos 313 (Bertomeu Bonet); 1395, enero 14, donde Pere Centelles, hijo de Toda de Vilanova, y esposo de Ramoneta de Riusec aparece anotado como "domino baroniarum Nules et de Oliva".

(31) No consideramos necesario hacer una relación exhaustiva de todas las campañas en las que participó el linaje, pero una rápida lectura del Libre de memories de diversos sucesos 
e fets memorables e de coses senyalades de la ciutat e Regne de Valencia. 1308-1644. Introducció i nótes per Salvador Carreres i Zacarés, Valencia, 1930, puede dar una imagen más que válida, porque las noticias cronísticas que anota están corroboradas y contrastadas con transcripciones de los Manuals de consells de la ciudad. Cfr. también Capmany y de Montapalau, Antonio: Antiguos tratados de paces y alianzas entre algunos reyes de Aragón y diferentes príncipes infieles de Asia y África, desde el siglo XIII hasta el $X V$. Reimpresión facsímil de la edición realizada en Madrid en 1786, Valencia, 1974. Índices por José Hinojosa Montalvo, p. 24.

(32) Cfr. Escolano, G. Op. cit., col. 560 n. ${ }^{\circ} 10$ hasta col. 166 n. ${ }^{\circ} 13$. La participación en las campañas de Sicilia hicieron a Gilabert Centelles señor de la villa y castillo de Ferula; Cfr. también Mitjà, Marina: «Procés contra els consellers, domèstics i curials de Joan I, entre ells Bernat Metge». B. R. A. B. L. B. 27, Barcelona, 1957-1958, p. 375-417.

(33) Crr. Camarena Mahiques, José Op. cit. p. 165; y también Metge, Bernat: Lo somni. A cura de Marta Jordà. Pròleg de Giusseppe Tavani, Barcelona, 1986, p. 10-12.

(34) Cfr. Escolano, G. Op. cit. col. 750 n. ${ }^{\circ}$ 2; y Teixidor, J. Op. cit. vol I. p. 151-152.

(35) En efecto, los Centelles sólo ostentaron el cargo de capitán de tropas o de naves de la ciudad en los momentos en que ésta debía participar en las campañas regias. Tan sólo en una ocasión - desde 1356- un Centelles regentó un puesto de carácter «civils: en 1414, Bernat Centelles fue designado por el Consell como misatger en una embajada al Papa.

(36) Queda fuera de toda duda una posible equiparación de esta calta» nobleza valenciana con las más altas instancias de este mismo estamento en Aragón o en Castilla. Las diferencias son ostensibles ya que las propias características de la conquista redujeron el protagonismo de la nobleza dentro de la vida interna del reino. De todos modos, los Centelles, dentro de la jerarquía nobiliaria del reino de Valencia, ocuparon los últimos escalones de la pirámide. Cfr. Noguera Aquevera, Vicente - Martínez Aloy, José: «Los barones del reino de Valencia. Estudio histórico». Revista de Valencia 2, Valencia, 1882, p. 282-299.

(37) En nuestra tesis de licenciatura ya pudimos comprobar como los enfrentamientos entre los nobles del reino llegaban incluso a obtener partidarios entre los miembros de los oficios, entre los mudéjares e incluso entre los "delincuentes habituales». Al grito de Centelles o Vilaragut acudía un numeroso grupo de hombres armados con una extracción social muy diferente. Cfr. Narbona Vizcaíno, Rafael: Violencia, Malhechores y Justicia urbana. 13601399, Valencia, 1990. Obra galardonada en el XXX Premio Senyera de Investigaciones Históricas, otorgado por el Excmo. Ayuntamiento de Valencia. Del mismo modo, nos aproximamos al estudio de los partidos políticos en Valencia en nuestra comunicación «Gobierno político y luchas sociales: patricios y malhechores", en el Congreso Lluís de Santàngel $i$ el seu temps, celebrado en Valencia entre el 5 y el 8 de octubre de 1987. Saitabi (1990). En prensa.

(38) El Dietari del capellà... Op. cit. indica que la defunción se produjo a mediados de agosto de 1418. p. 115. No obstante, documentalmente está consignado como difunto el 25 de enero de 1417. Cfr. A. M. V. Manuals d'albarans de claveria censals I-36. Sobre la descendencia del iniciador de la línea de los marqueses de Dos Aguas Cfr. Teixidor, J. Op. cit. vol. I p. 51.

En 1409 Caterina todavía era una niña de escasa edad, pues Giner Rabassa, caballero, pagó el último plazo de las 18 libras adeudadas a Guillem Berbegal y su esposa Isabel, vecinos de Valencia "pro lectando Caterinetam, neptam sive neta vestram, filiam nobilum Francisci de Perellos et domine Johanne Rabassa, filii vestre, pro tempus unius anni qui incepit a festo beati Matheim. Cfr. ARV. Protocolos 1848 (Arnau Puig): 1409, octubre 10.

(39) Cfr. García Carrafa, A. Op. cit. vol. III, p. 300-302. Y también Cfr. los trabajos de Caruana y Reig, José: Los Proxida y el estado de Almenara Op. cit. p. 7 cuadro 1, y p. 16-18. Cfr. también Las casonas solariegas... Op. cit., donde inserta una genealogía del linaje Carroz.

(40) García de Carrafa, A. Op. cit.; Libre de memories... Op. cit. p. 56; Dietari del capellá... Op. cit. p. 117, y p. 139-140; y Gubern, Ramón: Epistolari de Pere I/I Barcelona, 1955, p. 170-174. 
(41) Una somera relación queda recogida por Pere María Orts y Bosch en la Enciclopedia de la región valenciana $O p$. cit.

(42) Existen varias versiones del incidente. Por ejemplo Cfr. Crónica de Pere Maça. Edición, notas e indices por José Hinojosa Montalvo, Valencia, 1979, p. 41; y Sevillano Colom, Francesc: El Centenar de la ploma de la ciutat de València. 1365-1711 Barcelona, 1966, p. 29.

(43) Cfr. Escolano, G. Op. cit. Sobre los títulos de vizconde de Roda y de vizconde de Perellós. Cfr. Sobrequés Vidal, Santiago: «La nobleza catalana en el siglo XIV». A. E. M. Barcelona, 1970-1971, p. 518.

(44) Por ejemplo, Gilabert de Centelles ejerció de "gerenti vices gubernatoris in regno Valentie» durante el reinado de Jaime II. Cfr. Llibre Blanc de la Governació. Edición de Desamparados Pérez Pérez, Valencia, 1971, doc. 49, otorgado en Barcelona el 20 de agosto de 1318 , p. $92-93$.

(45) Cfr. el catálogo de documentos de Jaime I elaborado por J. E. Martínez Ferrando Op. cit., en especial el doc. n. ${ }^{\circ} 1816$, datado el 19 de abril de 1275.

(46) De todos modos, hemos de indicar que la rama ciudadana de los Ripoll está documentada con Berenguer Ripoll, notario, conseller de parroquies de San Esteban en 1372 y en 1381; Guillem Ripoll conseller de parroquies de San Lorenzo en 1366; y Pere Ripoll conseller de parroquies de Santo Tomás en 1380 y 1382, conseller de parroquies por San Salvador en 1399, y conseller d'oficis por los notarios en 1388.

(47) En 1369 Jofre habria de poseer al menos los 25 años necesarios para ser nominado candidato parroquial en las elecciones a Jurados. Por tanto en 1405, cuando ya es consignado como difunto, tendría al menos setenta y un años.

(48) En la primera mitad del siglo ejercieron un importante número de magistraturas municipales como ciudadanos.

Cargos

Jurat cavaller

\begin{tabular}{c} 
N. de veces \\
\hline 4 \\
8 \\
7 \\
2 \\
2 \\
\hline
\end{tabular}

Conseller.de cavallers

22 puestos

(49). Cfr. la edición de José María Doñate Sebastiá del libro llamado del Bien y del Mal Op. cit; Cfr. Carreres i Zacarés, Salvador: Notes per a la historia dels bandos... Op. cit. p. 25; y también Cfr. Diago, Francisco O. P.: Apuntamientos Op. cit. p. 50, 79 y 199.

(50) Ese censal fue comprado a razón de $\$ 4.000$ por mil. Berenguer de Ripoll entregó 112.000 sueldos al municipio (mil libras en dinero líquido y en resto en draps), a cambio de los cuales recibiría una pensión anual de 8.000 sueldos. Es decir, en 1356, el primer censal vendido por la ciudad estipula un interés del 7,14\% Cfr. Libre de memories... Op. cit. p. 49.

(51) En este sentido, Cfr. Villalonga Villalba, Ignacio: Régimen municipal foral valenciano. Los Jurados y el Consejo Valencia, 1916. Y también el capítulo I y II de nuestra tesis doctoral Op. cit.

(52) La primera referencia como mossen y cavaller pertenece a 1408. Cfr. Libre de memories... Op. cit. p. 283, 305, y 377 . A pesar de que su carrera política «finalice» en 1407 todavía sigue vivo en 1421, cuando aparece realizando una operación privada de compra-venta de censales. Cfr. A. R. V. Protocolos 312 (Bertran de Boes): 1421, marzo 13.

(53) Desconocemos la vinculación de $\mathrm{Na}$ Rois con el resto de miembros del linaje Ripoll, a pesar de los esfuerzos realizados para documentarla. Tan sólo Teixidor se hace eco de su existencia, aunque en una cronología tardía. Cfr. Capillas y sepulturas del real convento de Predicadores... Op. cit. vol. I, p. 240-242.

(54) Cfr. Dietari del capellà... Op. cit. p. 100. Sobrino del difunto fue Joan Ferrandiz de Heredia, que junto a Blasco Ferrandiz de Heredia, encabezaban en Zaragoza la lucha de una facción de la nobleza aragonesa contra los urgelistas. Cfr. Vendrell de Millàs, Francesca - Masià de Ros, Angels: Jaume el dissortat, darrer comte d'Urgell Barcelona, 1956, p. 49, 112 y 116-117. Cfr, también ARV. Protocolos 2350 (Andreu Vidal): 1372, marzo 24. 
(55) Del matrimonio entre Manuel Díez de Calatayud "lo antich", señor de Andilla, y Caterina Vilanova nacería: Manuel Díez «lo modern», que moriría sin hijos; Ferrando Diez, comana. dor de la Orden de San Juan del Hospital; Joana Díez, que casó con Francesc Hieroni Ferrando.

La unión entre los Diez y los Ferrandiz de Heredia tendría una prolija descendencia, según queda reflejado en el árbol genealógico que Gaspar Gil Polo introduce al final de la obra La Diana enamorada. Cinco libros que siguen los VII de Jorge de Montemayor. Edición de Francisco Cerdá y Rico, Madrid, Imprenta de Antonio de Sancha, 1778.

(56) Cfr. A. M. V. Manuals d'albarans de claveria comuna 1-1: 1367, octubre 27. Sin embargo, existen noticias anteriores que indican que Giner Rabassa major pertenece al escalafón de la nobleza menor, porque en las Cortes de 1364 asistió como síndico delegado por la ciudad de Valencia, haciéndose constar que era generoso.

(57) Cfr. Idem, 1-10: 1378, septiembre 1; I-19: 1392, marzo 29; y J-5: 1408, enero 26.

(58) Cfr. Carboneres, Manuel: Nomenclator de las puertas, calles y plazas de Valencia Valencia, Imprenta Avisador Valenciano, 1873, p. 103. Los cargos de Jurado fueron ejercidos por las parroquias de Santa María y San Pedro: en 1357 (padre) y 1378 (hijo).

(59) Entre 1356 y 1419 los Rabassa sólo están representados en el municipio por Arnau, que ejerció de conseller de parroquies en 1364 y 1370 por San Bartolomé, y por micer Jaume, que ejerció de Jurado en 1378-1379.

(60) Prueba de ello es el actual palacio del marqués de Dos Aguas, donde actualmente se encuentra ubicado el Museo Nacional de Cerámica González Martí. Todavía a principios del siglo XVIII conservaba su arquitectura medieval e incluso su torre. Cfr. J. Caruana y Reig: Las Casonas... Op. cit., y todavía se puede comprobar en el plano original realizado por el padre Tosca a principios del citado siglo, conservado en el A. M. V.

(61) Cfr. A. M. V. Manuals d'albarans de claveria comuna 1-3: 1370, abril 3.

(62) Cfr. los Apuntamientos... Op. cit. de Diago, vol. II, p. 112. Según este autor, a su muerte sería vendida esta propiedad a Jaume Romeu para pagar la dote de su hija Joana a Pere de Centelles. No obstante, la cronología que indica no es válida, ya que Pere cobraría la dote dos años después de su muerte. Además Giner major fallecería en torno a 1382.

(63) Según indica Sobrequés, en un principio el término home de paratge venía a designar al campesino libre, propietario, que era capaz de pagarse cabalgadura y armas. Era pues del todo equiparable a los caballeros villanos o caballeros pardos de Castilla. Sin embargo, pronto se desvirtuaría el término porque poco a poco irá aplicándose a los nuevos señores territoriales, especialmente ciudadanos que van adquiriendo propiedades en el término de la ciudad. Cfr. Sobrequés y Vida, Santiago: “La nobleza catalana...» Op. cit. p. 514.

En 1409 Giner Rabassa, caballero y habitador de Valencia, todavía era señor del molino «d'en Company» Cfr. ARV. Protocolos 1848 (Arnau Puig): 1409, octubre 10.

(64) Cfr. la edición de J. M. ${ }^{a}$ Doñate Sebastia del libro del bien y del mal Op. cit.; Sevillano Colom, Francisco: Valencia urbana medieval a través del oficio de Mostaçaf, Valencia, 1957, p. 18-20; Enciclopedia de la región valenciana Op. cit.; Muñoz Pomer, Rosa: Orígenes de la Generalidad Valenciana, Valencia, 1987; y el Libre de Memories... Op. cit. p. 18. Sobre Giner menor Cfr. también Vidal Beltrán, Eliseo: Valencia en la época de Juan I, Valencia, 1974 , p. 99, nota 26.

(65) Sobre estas obras Cfr. Cebrián Ibor, Santiago: «Los fueros de Valencia». III. ${ }^{\circ}$ C. H. C. A., Valencia, 1923, vol. I, p. 662-663, y de modo más amplio en su obra Los fueros de Valencia. Apuntes preliminares para su exposición y estudio completo, Valencia, 1925. También Cfr. Beneyto Pérez, Juan: «Elementos constitutivos de las redacciones medievales de "Notae super foris Regni Valentie"». A. C. C. V. 1, Valencia, 1940, p. 20 y 28.

(66) Como dijimos con anterioridad la primera referencia como difunto pertenece al 5 de febrero de 1382. Cfr. A. M. V. Manuals d'albarans de claveria comuna I-12. El cargo de Advocat pensionat incluso sería compaginado con otros de índole política. Por ejemplo, en 1371, Giner major habia sido electo Jurado por los caballeros. A lo largo de toda una anualidad 
compaginará los dos puestos, e incluso percibirá dos salarios distintos: mil sueldos como Jurado y otros tantos como abogado pensionado. Cfr. Idem, l-4 (1371, febrero 25), e I-5 (13 de septiembre, 21 de octubre, y 19 de diciembre del mismo año).

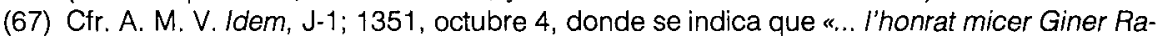
bassa, licenciat en leys, asesor del batle general del Regne de Valencia..,» percibe 100 sueldos de las arcas municipales, en concepto de salario por una sentencia de un proceso que mantiene la ciudad y un judío de Mallorca por la exportación fraudulenta de cereales.

(68) Cfr. Vidal Beltrán, Eliseo Op. cit.p. 144 y 157; y también Gual Camarena, Miguel: «Los abogados de la ciudad de Valencia en el siglo XIV. Notas y documentos». VIII. ${ }^{\circ}$ C. H. C. A. vol. Il (1967), p. 221-240.

(69) En el caso concreto de micer Giner Rabassa major podemos comprobar como en 1381 , un año antes de su defunción ha sido reelegido por el Consell para seguir desempeñando el cargo. Cfr. A. M. V. Manuals d'albarans de claveria comuna I-12: 1381, octubre 8.

(70) Cierto es que el derecho puede ser considerado como el sistema o conjunto de normas reguladoras de los comportamientos humanos en la sociedad, por lo que constituye una técnica de organización social que implanta un determinado orden en el que se albergan una serie de intereses. "... Puede decirse en este sentido que todo Derecho deriva de un determinado sistema de intereses y valores, y que inversamente, todo sistema de legitimidad intenta realizarse a través de un determinado sistema de legalidad...» Cfr. Díaz, Elías: Sociologia y filosofía del Derecho (Madrid, 1982), p. 11-12.

(71) Cfr. Rodrigo Lizondo, Mateo: La Unión valenciana y sus protagonistas». Ligarzas 7, Valencia, 1975, p. 133-166. Dos de las seis plazas de conservadors correspondian a los juristas, sin que existiera precedente alguno en una representación «profesional»s similar en el ejecutivo ciudadano.

(72) La coronación de Alfonso $V$ supuso la inauguración de un nuevo sistema electoral para acceder a las magistraturas municipales, pero también suponía la reestructuración de los órganos institucionales del poder municipal. En 1419 cobra forma institucionalmente el Consell secret o ejecutivo ciudadano que se reserva todo el poder decisorio. En él quedan integrados los seis Jurados, el Racional, el Síndico, el Escribano y los Abogados pensionados y ordinarios del Consell.

(73) Este dato lo aporta Roca Traver, José: Ordenaciones municipales de Castellón de la Pla. na... Op. cit. p. 158.

(74) Cfr. Vidal Beltrán, E. Op. cit. p. 158.

(75) El asesoramiento en materia jurídica sin duda estuvo intimamente ligado a la decisión polftica de Pedro IV para reincorporar Mallorca a la Corona de Aragón. Sobre la participación de Giner Rabassa Cfr. Libre de memories... Op. cit. p. 12-18.

(76) Desde esa fecha Giner Rabassa menor es consignado como doctor en leys de la dita ciutat, como asesor del Gobernador, delegado por las partes litigantes, y como juez nombrado por el mismo monarca en determinados procesos. Cfr. A. M. V. Manuals d'albarans de claveria comuna l-19 (1391, julio 1 y 1392, marzo 29), I-29 (1401, mayo 20); Llibre Blanc de la Governació... Op. cit. doc. 23 p. 51-53. Del mismo modo, Giner Rabassa major en 1360 también ejerció de asesor de la Gobernación por la cuestión derivada de las «escorrenties dels arroços" en Paterna, aunque en realidad era Advocat de la ciutat. Cfr. Libre de memories... Op. cit. p. 69.

(77) La fecha la aporta Dualde Serrano, Manuel: La elección de los compromisarios de Caspe. Tirada aparte de la Escuela de Estudios Medievales. C. S. I. C., Zaragoza, 1949, p. 361, nota 8 y p. 364 .

(78) En este sentido Cfr. Gómez Martí, Pedro: «Sobre un síntoma mental de Giner Rabassa». III. ${ }^{\circ}$ C. H. C. A., Valencia, 1923, vol. I, p. 273-278. Sobre el proceso donde se declara su alineación mental Cfr. Biblioteca Universitaria de Valencia. Manuscrito 40, en cuya tapa figura el siguiente título: «Procés de elecció del rey Ferrando I en Aragón. 1410». 
(79) Sobre los «técnicos de la administración» en la Edad Media Valenciana pueden verse los trabajos de J. M. Cruselles Gómez.

(80) Este fenómeno de promoción social en la Baja Edad Media Valenciana ha sido estudiado en épocas posteriores. Antoni Lopiz, notario, llega a ennoblecer a su familia en una generación. Sus hijos, abogados, llegan a ser caballeros en el segundo tercio del siglo XV. La vía de promoción había sido el servicio al linaje de los Borja. Cfr. Cruselles Gómez, J. M. ${ }^{\text {a }}$ La familia de Antoni Lopiz, notario de la ciudad de Valencia. 1433-1493. Promoción social de un profesional de la escritura. Tesis de licenciatura inédita (Valencia, 1985). Este mismo fenómeno puede observarse pues en el linaje Rabassa con un siglo de anterioridad y al servicio de las instituciones de poder de la Valencia foral. 